International Journal of Clinical Therapeutics and Diagnosis (IJCTD)

ISSN 2332-2926

\title{
An Epidemiological Approach to the Study of Alzheimer's Disease
}

EA Perry ${ }^{1}$, RJ Castellani ${ }^{2}$, G Perry $^{3 *}$

Editorial

${ }^{1}$ National Institute of Dental and Craniofacial Research Institute, Bethesda, MD, USA.

${ }^{2}$ Department of Pathology, University of Maryland, Baltimore, MD, USA.

${ }^{3}$ College of Sciences, TheUniversity of Texas at San Antonio, San Antonio, TX, USA.

\section{*Corresponding Author:}

G Perry,

College of Sciences, TheUniversity of Texas at San Antonio, San Antonio, TX, USA.

E-mail: George.Perry@utsa.edu

Received: May 06, 2014

Published: May 21, 2014

Citation: EA Perry, RJ Castellani, G Perry (2014) An Epidemiological Approach to the Study of Alzheimer's Disease. Int J Clin Ther Diagn. 2(1e), 1. doi: http://dx.doi.org/10.19070/2332-2926-140002e

Copyright: G Perry ${ }^{\circ}$ 2014. This is an open-access article distributed under the terms of the Creative Commons Attribution License, which permits unrestricted use, distribution and reproduction in any medium, provided the original author and source are credited.

The prevalence of Alzheimer's disease (AD) has increased dramatically in recent years. A condition that was essentially absent from pathology texts but thirty years ago is now a major concern for the aging population. Billions of dollars have been invested in a cure for a disease that is still poorly understood. Indeed, current strategies target the effects of the disease, rather than the cause. An epidemiological approach towards understanding AD involves asking questions that build a web of ideas. What are the risk factors in populations that are highly susceptible to AD? Should scientists be following a genetic determinant such as the apolipoprotein E genotype? Or is lifestyle playing a much larger role in the onset of the disease?

Translational research may be able to fill in the gaps in our understanding of the disease. The foods we consume, medications we take, water we drink and air we breathe are all a facet of the shifts in culture. As Western culture spreads globally, so does Western illnesses such as heart disease, type 2 diabetes, and AD. Perhaps the best way to analyze the causes of $\mathrm{AD}$ is to first understand the changes in the affected population prior to the onset of disease. Bridging population genetics, anthropology and biochemistry may provide the answers to AD's biggest questions. 